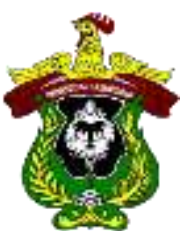

\title{
MENGANALISIS KARAKTERISTIK SEDIMEN DAN MORFOLOGI MUARA SUNGAI KAPUAS GUNA MEMPERLANCAR ALUR PELAYARAN
}

\author{
*Farid Budiman, Yudha Setyawan dan Aditya Ando Yosafat \\ Jurusan Teknik Kelauatan, Fakultas Teknik, Universitas Tanjungpura \\ *fbudiman@gmail.com
}

\begin{abstract}
Abstrak
Muara sungai merupakan tempat pertemuan antara air laut dengan air sungai dan merupakan bagian hilir dari sungai. Pada dasar perairan muara sungai terjadi pengendapan, karena terjadi pertemuan partikel pasir/lumpur yang dibawa oleh arus sungai bertemu dengan pasir berada di daerah sekitar pantai. Berkaitan dengan hal tersebut, maka sangat penting untuk meneliti karakteristik dari muara serta karakteristik sedimennya, khususnya untuk memberikan informasi kepada masyarakat sekitar serta memberikan data mengenai karakteristik sedimen yang mengendap untuk menentukan metode pengerukan yang lebih efisien atau mencari solusi agar tidak dilakukan pengerukan tiap tahunnya. Penelitian ini dilaksanakan di Laboratorium Mekanika Tanah Fakultas Teknik Universitas Tanjungpura serta pada penggambilan sampel sedimen di Muara Sungai Kapuas. Waktu pengambilan sampel sedimen pada 9 titik dan pengambilan data batimetri pada 21 titik adalah tanggal 14 juni 2019 sedangkan untuk uji laboratorium pada tanggal $14-22$ juni 2019. Metode yang digunakan ialah purpose sampling untuk mengambil sampel di lapangan, metode kuantitatif untuk pengujian di laboratorium. Untuk analisa data menggunakan metode sistem USDA dan kategori kemiringan Van Zuidam. Dari hasil pengambilan data lapangan, menunjukkan bahwa batimetri di Muara Sungai Kapuas berkisar antara 2,6 m hingga 8,7 m pada MSL +0,8 m dengan kontur dasar di Muara Sungai Kapuas di kategorikan Datar. Jenis sedimen dasar di Muara Sungai Kapuas didominasi oleh kategori tanah liat berlanau. Sedimen bisa berasal dari pantai berlumpur yang mengalami abrasi oleh aliran air. Oleh karena itu, solusi agar tidak dikeruk setiap tahunnya maka perlu dibangun Jetty atau dinding penahan pantai.
\end{abstract}

Kata Kunci: Bottom Sediment, Bathymetry, Navigation Channel, Kapuas Estuary.

\begin{abstract}
A river estuary is a meeting place between sea water and river water and is a part of the river downstream. At the bottom of the river estuary, sedimentation occurs, because there is a meeting of sand / mud particles carried by river currents that meet with sand in the area around the coast. In this regard, it is very important to examine the characteristics of the estuary and its sediment characteristics, especially to provide information to surrounding communities and provide data on sediment characteristics that settle to determine more efficient dredging methods or find solutions so that dredging is not carried out annually. This research was conducted at the Soil Mechanics Laboratory of the Faculty of Engineering, Tanjungpura University, and in taking sediment samples at the Kapuas River Estuary. The time for taking sediment samples at 9 points and taking bathymetry data at 21 points is June 142019 while for laboratory tests on June 14-22, 2019. The method used is purpose sampling to take samples in the field, quantitative methods for testing in the laboratory. For data analysis using the USDA system method and the Van Zuidam slope category. From the results of field data collection, it was shown that bathymetry in the Kapuas River Estuary ranged from $2.6 \mathrm{~m}$ to $8.7 \mathrm{~m}$ at MSL + $0.8 \mathrm{~m}$ with the base contour in the Kapuas River Estuary categorized as Flat. The type of base sediment in the Kapuas River Estuary is dominated by the category of clay soil. Sediments can originate from muddy beaches that experience abrasion by water flow. Therefore, the solution so that it is not dredged annually, it is necessary to build a Jetty or coastal retaining wall.
\end{abstract}

Keywords: Bottom sediment, Bathymetry, Navigation Channel, Kapuas Estuary.

copyright is published under Lisensi Creative Commons Atribusi 4.0 Internasional. 


\section{PENDAHULUAN}

Muara sungai merupakan tempat pertemuan antara air laut dengan air sungai dan merupakan bagian hilir dari sungai [1]. Pada dasar perairan muara sungai terjadi pengendapan, karena terjadi pertemuan partikel pasir/lumpur yang dibawa oleh arus sungai bertemu dengan pasir yang berada di daerah sekitar pantai [2]. Dengan demikian percampuran pasir tersebut menghasilkan pengendapan lumpur yang sangat berpengaruh pada perilaku kehidupan organisme muara sungai. Selain itu salinitas yang terbentuk di muara sungai merupakan campuran antara salinitas air sungai dengan salinitas laut [3].

Sungai-sungai yang bermuara pada pantai berpasir dengan gelombang cukup besar sering mengalami penyumbatan muara sungai oleh endapan pasir [4] . Karena pengaruh gelombang dan angin, endapan pasir terbentuk di muara sungai. Pengiriman sedimen sepanjang pantai juga sangat berpengaruh terhadap pembentukkan endapan tersebut [5] . Pasir yang melintas di depan muara sungai akan terdorong oleh gelombang masuk ke muara sungai dan kemudian diendapkan. Endapan yang sangat besar dapat menyebabkan tersumbatnya muara sungai [6] . Penutupan tersebut terjadi pada musim kemarau dimana debit sungai kecil sehingga tidak mampu mengerosi endapan [7]. Penutupan muara sungai tersebut dapat menyebabkan terjadinya banjir di daerah sebelah hulu muara sungai. Pada musim penghujan air banjir dapat mengerosi endapan sehingga sedikit demi sedikit muara sungai terbuka kembali [8] . Selama proses penutupan dan pembukaan kembali tersebut biasanya disertai dengan membeloknya muara sungai dalam arah yang sama dengan arah pengiriman sedimen sepanjang pantai [9]. Jetty dapat digunakan untuk menanggulangi masalah tersebut.

Berkaitan dengan hal tersebut, maka sangat penting untuk meneliti karakteristik dari Muara Sungai Kapuas serta karakteristik dari sedimennya sendiri, khususnya untuk memberikan informasi kepada masyarakat sekitar muara sungai tersebut agar masyarakat mengetahui karakteristik batimetri dari Muara Sungai Kapuas serta memberikan data mengenai karakteristik sedimen yang mengendap untuk menentukan metode pengerukan yang lebih efisien atau mencari solusi agar tidak dilakukan pengerukan tiap tahunnya. Berdasarkan pemaparan tersebut, peneliti tertarik mengangkat judul penelitian mengenai "Menganalisis Karakteristik Sedimen Dan Morfologi Muara Sungai Kapuas Guna Memperlancar Alur Pelayaran”. Dalam penelitian ini, tidak hanya diteliti mengenai karakteristiknya saja, namun peneliti juga meneliti sedimen dari muara tersebut, kemudian morfologi dasar dari Muara Sungai Kapuas atau batimetri. Nantinya, penelitian ini diharapkan dapat memberi informasi kepada masyarakat sekitar Muara Sungai Kapuas pada khususnya dan masyarakat luas pada umumnya.

\section{METODE}

Penelitian ini dilaksanakan di Laboratorium Mekanika Tanah Fakultas Teknik Universitas Tanjungpura serta pada penggambilan sampel sedimen di Muara Sungai Kapuas dan waktu dilaksanakannya penelitian adalah selama 3 bulan yang terhitung mulai dari studi pustaka dengan dosen pembimbing, pengambilan dan penelitan sampel, pengujian hasil penelitian di laboratorium sampai penyusunan laporan akhir. Untuk pengambilan sampel sedimen dan pengambilan data batimetri pada tanggal 14 juni 2019 sedangkan untuk uji laboratorium pada tanggal $14-22$ juni 2019.

Instrumen penelitian terdiri dari:

a. Laptop atau komputer, digunakan untuk menyimpan dan mengolah data hasil penelitian.

b. GPS, digunakan untuk menentukan titik koordinat dan menentukan elevasi muara.

c. Alat pengambil sampel sedimen.

d. Alat di Laboratorium Mekanika Tanah.

Metode dilakukan dalam penelitian ini adalah metode purpose sampling untuk mengambil sampel di lapangan, metode kuantitatif untuk pengujian di laboratorium berdasarkan teori yang dapat dipertanggungjawabkan, dan beberapa metode dalam melakukan beberapa analisa data [10]s .

Pengambilan sampel sedimen dilakukan di muara sungai Kapuas pada 9 titik. Alat yang digunakan yaitu alat untuk mengambil sampel sedimen. Kemudian hasil yang didapat di masukkan dalam plastik dan dibawa ke laboratorium untuk di uji beberapa pengujian. Uji yang dilakukan di laboratorium yaitu: uji kadar air, uji berat jenis tanah dan uji hidrometer saringan. Setelah didapat persentase kandungan jenis sedimen kemudian dilakukan pengklasifikasian menggunakan metode sistem USDA (United Stated Department of Agricultre), berdasarkan pada ukuran dari butiran tanah yang diterangkan sebagai berikut:

Pasir : Butiran dengan diameter $0,05 \mathrm{~mm}-2 \mathrm{~mm}$ 
Lanau : Butiran dengan diameter 0,002-0,05 mm

Lempung : Butiran dengan diameter $<0,002 \mathrm{~mm}$

Untuk menentukan besar persentase dari pasir, lanau, dan lempung, dapat dilihat dari grafik distribusi butiran tanah (Grain Size Distribution).

Selanjutnya pengambilan data batimetri menggunakan GPS dengan membaca elevasi dan mengetahui MSL saat pengukuran pada 21 titik, sepanjang $5 \mathrm{Km}$. Kemudian data batimetri tersebut di gambar menggunakan AutoCAD dengan skala vertikal dan skala horizontal. Kemudian dianalisis berdasarkan kategori kemiringan Van Zuidam dengan mengetahui persentase kemiringan atau derajat kemiringan.

\section{HASIL DAN PEMBAHASAN}

\subsection{Klasifikasi Sedimen Dasar Muara}

Penentuan klasifikasi sedimen menjadi bagian utama dalam penelitian ini dengan tujuan agar mengetahui jenis sedimen di muara sungai kapuas. Maka dari itu diperlukan penitikan lokasi pengambilan sampel di muara tersebut. Sempel sedimen diambil di 9 titik, pengambilan sampel yang dilakukan pada saat turun kelapangan menggunakan perahu sebagai alat transportasi dan juga sedimen grab sebagai alat pengambil sampel sedimennya. Kemudian sampel tersebut dibawa ke laboratorium mekanika tanah untuk di uji kadar air, berat jenis tanah, dan juga hidrometer saringan. Sampel dilakukan uji sebanyak 9 sampel pada masingmasing titik.

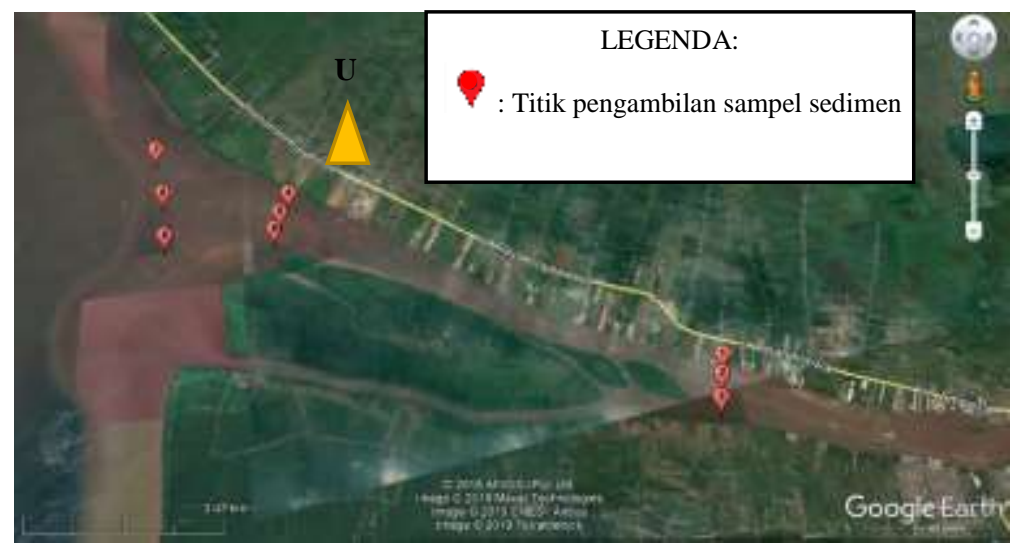

Gambar 1. Lokasi Pengambilan Sampel Sedimen

Sampel terlebih dahulu melalui uji kadar air dan berat jenis tanah dengan begitu untuk hasilnya akan digunakan saat penghitungan uji hidrometer saringan. Setelah melewati proses penyaringan maka sempel dapat di kategorikan pada masing-masing jenis tanah. Kemudian setelah dapat mendapatkan persentase kadar pasir, lanau dan juga lempungnya maka dilakukan klasifikasi sedimen menggunakan metode USDA. Berikut adalah grafik analisis saringan dan juga klasifikasi USDA masing-masing sampel.
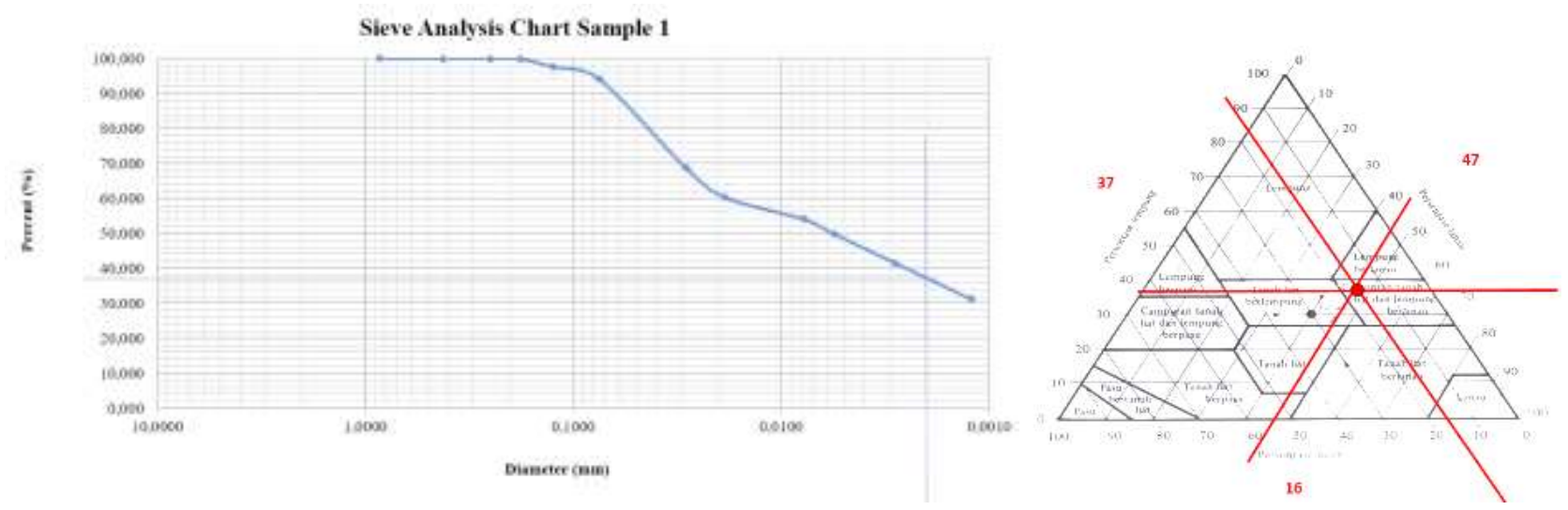

Gambar 2. Grafik dan Klasifikasi USDA Sampel 1 copyright is published under Lisensi Creative Commons Atribusi 4.0 Internasional. 

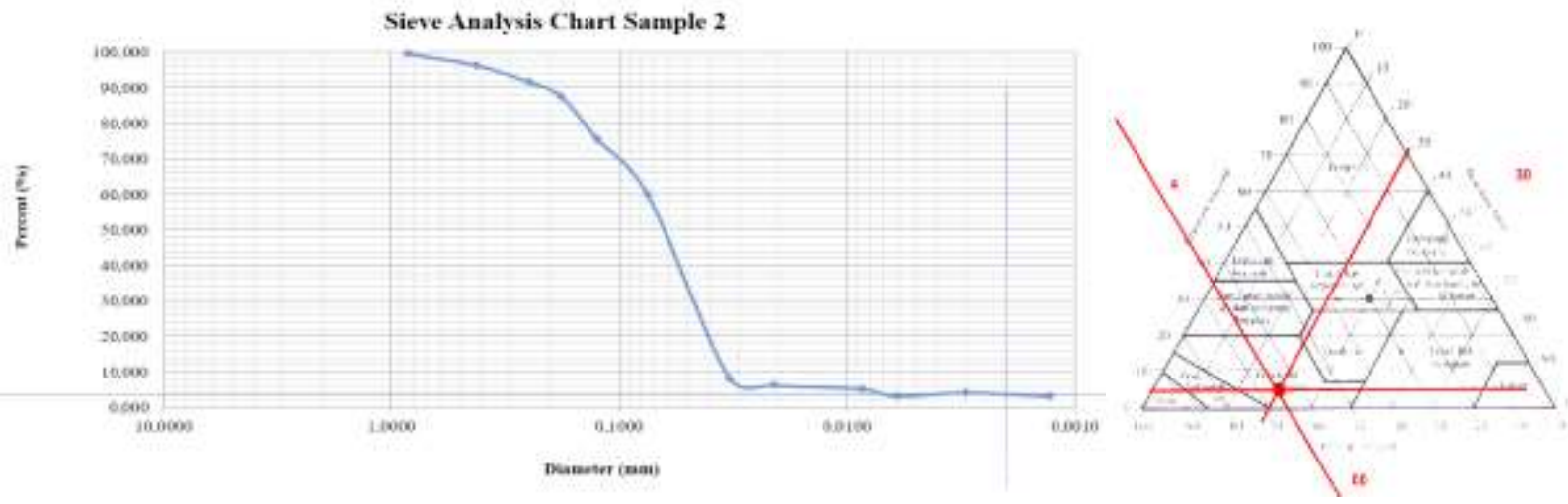

Gambar 3. Grafik dan Klasifikasi USDA Sampel 2
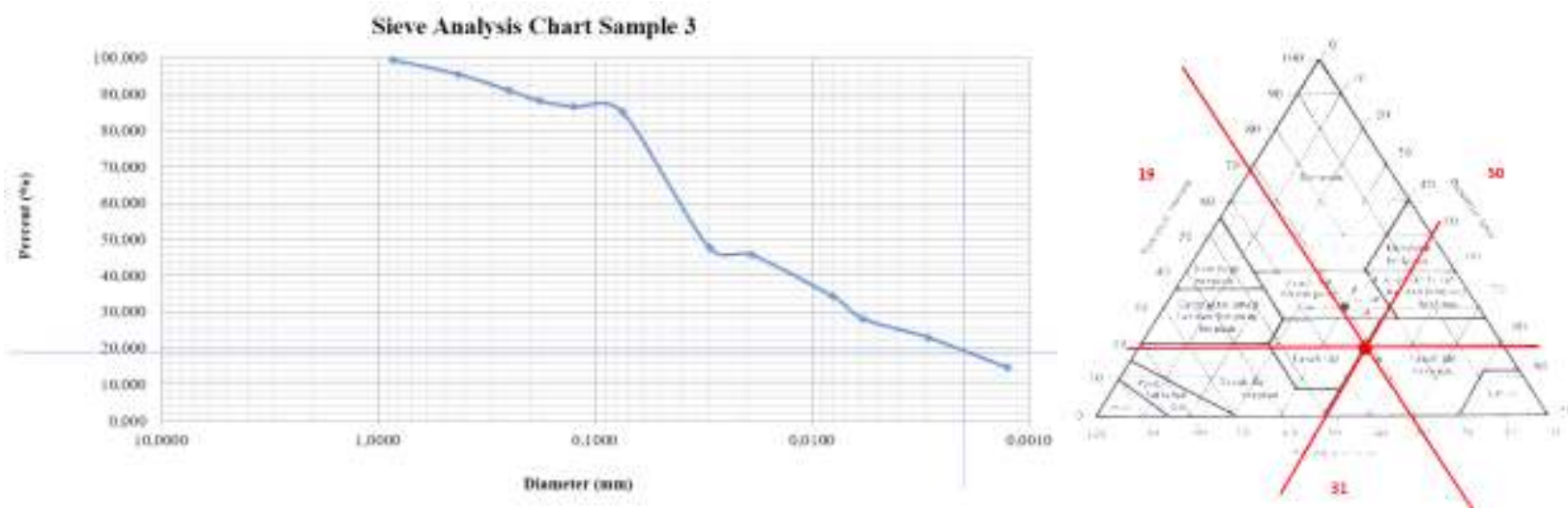

Gambar 4. Grafik dan Klasifikasi USDA Sampel 3

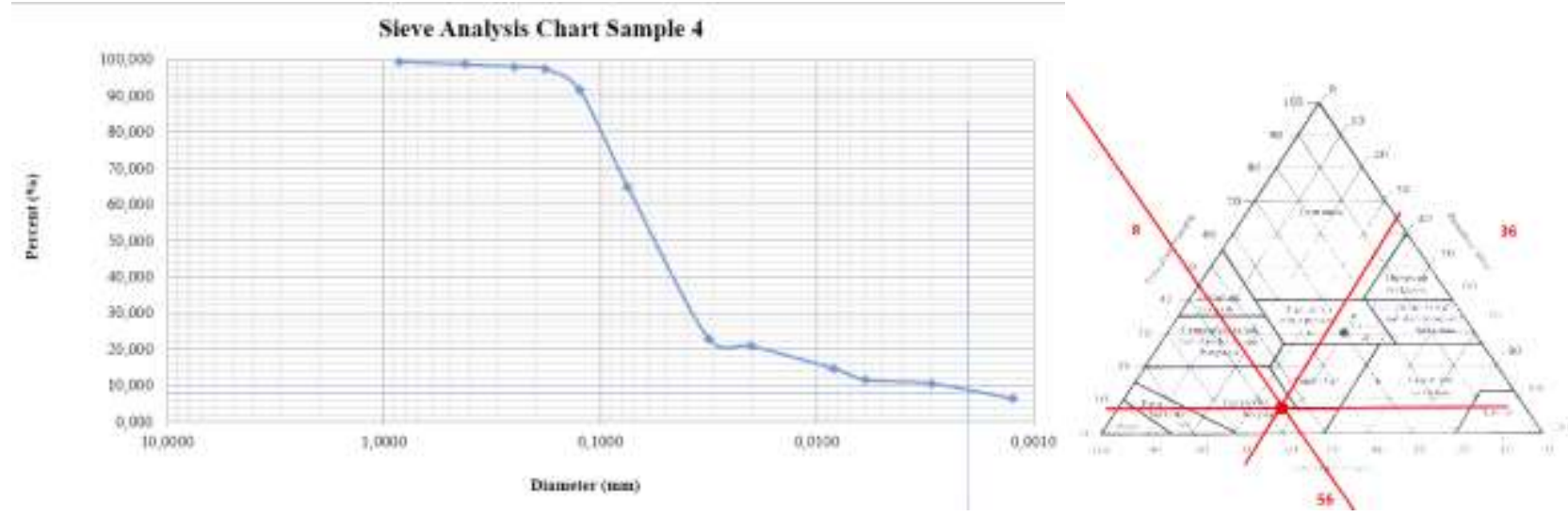

Gambar 5. Grafik dan Klasifikasi USDA Sampel 4
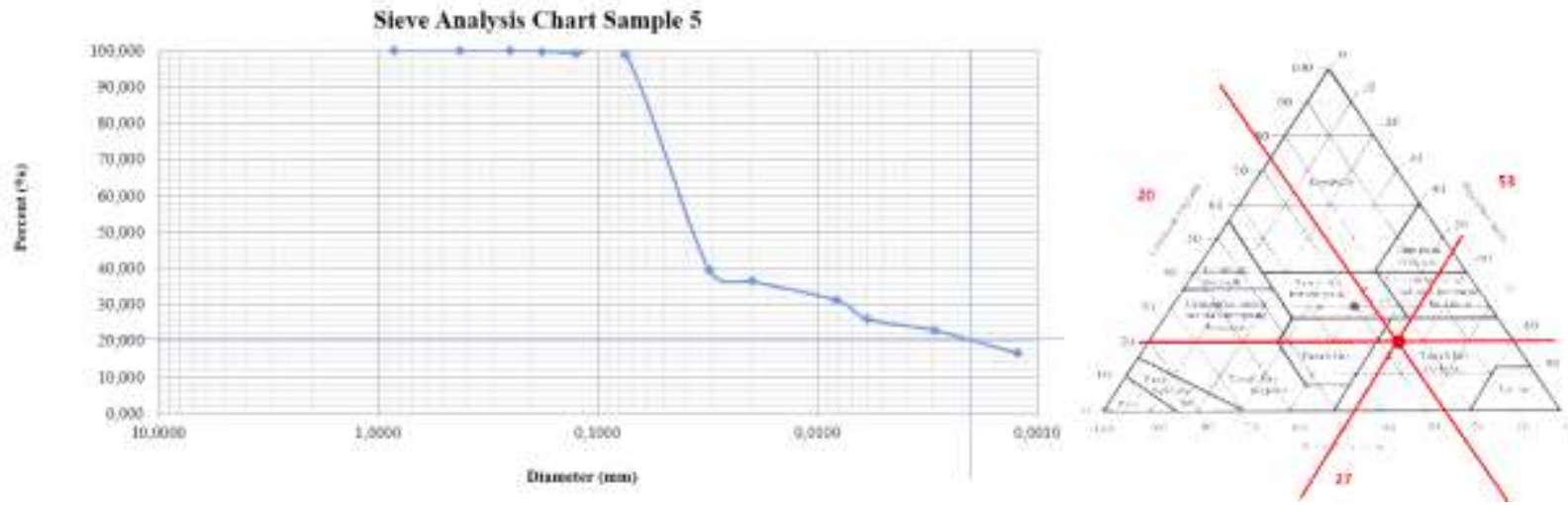

Gambar 6. Grafik dan Klasifikasi USDA Sampel 5 

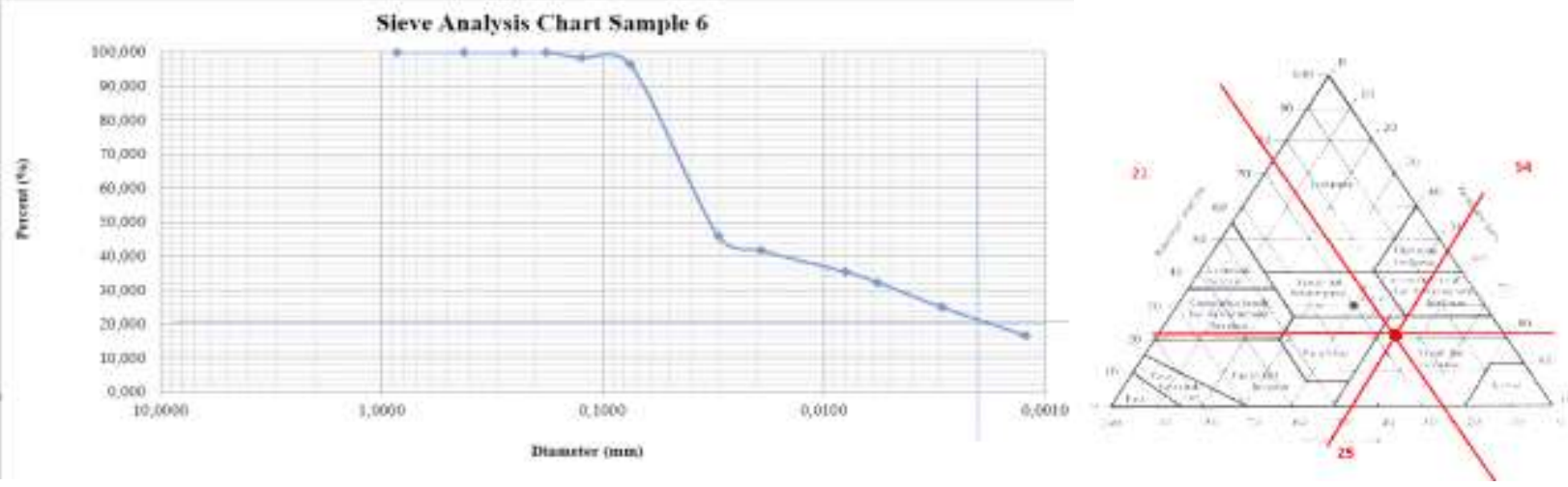

Gambar 7. Grafik dan Klasifikasi USDA Sampel 6
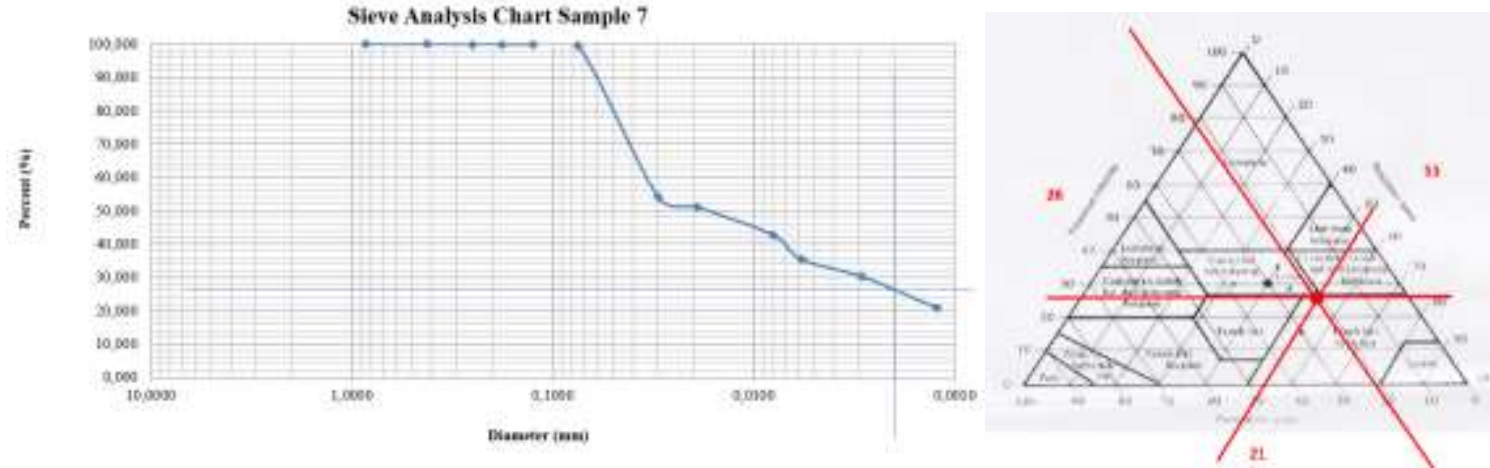

Gambar 8. Grafik dan Klasifikasi USDA Sampel 7
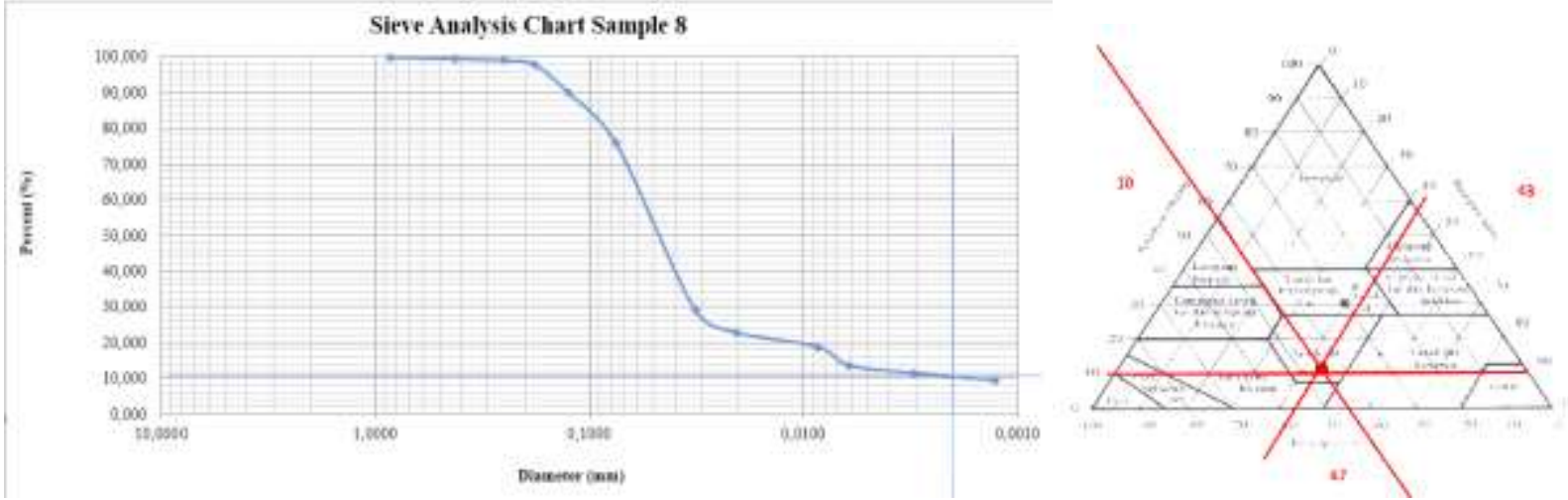

Gambar 9. Grafik dan Klasifikasi USDA Sampel 8
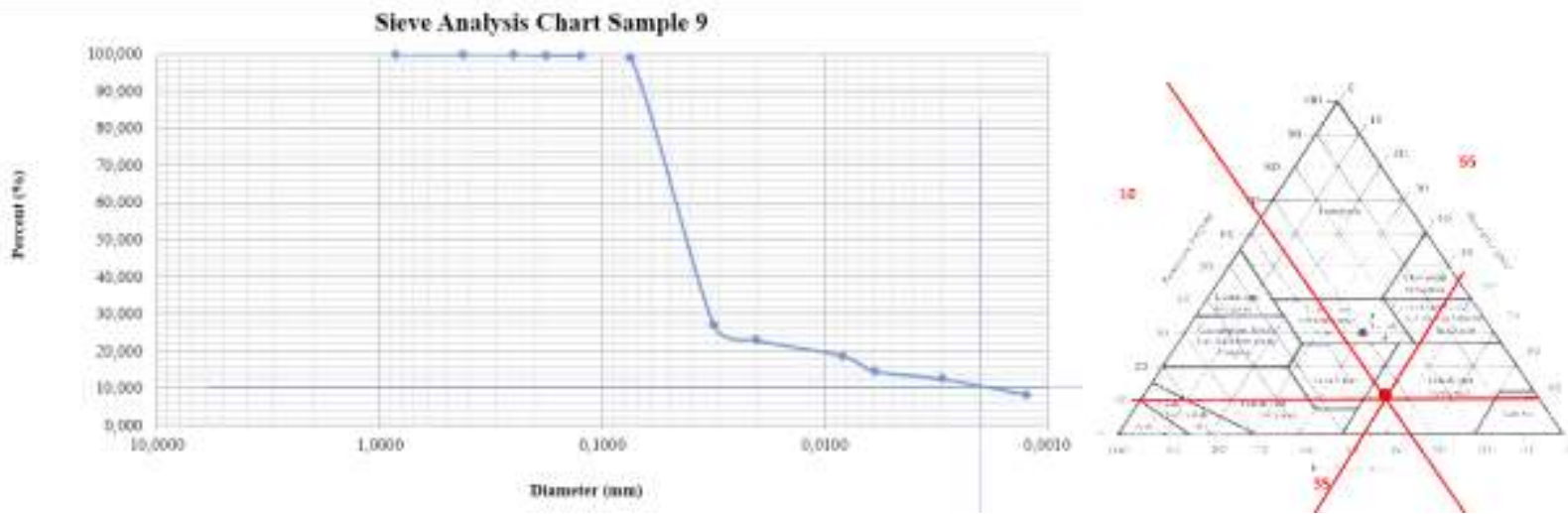

Gambar 10. Grafik dan Klasifikasi USDA Sampel 9

Hasil dari grafik dan klasifikasi tersebut tersaji dalam tabel.1.

(c) (i) copyright is published under Lisensi Creative Commons Atribusi 4.0 Internasional. 
Tabel 1. Klasifikasi Sedimen Dasar Muara Kapuas

\begin{tabular}{lllllll}
\hline $\begin{array}{l}\text { Spot } \\
\text { Sample }\end{array}$ & $\begin{array}{l}\text { Kadar Air } \\
(\%)\end{array}$ & Berat Jenis & \multicolumn{3}{l}{ Persentase Kandungan $(\%)$} & $\begin{array}{l}\text { Klasifikasi Sedimen } \\
\text { Berdasarkan Metode USDA }\end{array}$ \\
\cline { 5 - 7 } 1 & & & Pasir & Lanau & Lempung & \\
2 & 203 & 2,58 & 16 & 47 & 37 & $\begin{array}{l}\text { Campuran tanah liat dan } \\
\text { lempung berlanau }\end{array}$ \\
3 & 62 & 2,68 & 66 & 30 & 4 & Tanah liat berpasir \\
4 & 121 & 2,64 & 31 & 50 & 19 & Tanah liat berlanau \\
5 & 107 & 2,70 & 56 & 36 & 8 & Tanah liat berpasir \\
6 & 203 & 2,63 & 27 & 53 & 20 & Tanah liat berlanau \\
7 & 178 & 2,66 & 25 & 54 & 21 & Tanah liat berlanau \\
8 & 178 & 2,61 & 21 & 53 & 26 & Tanah liat berlanau \\
9 & 123 & 2,67 & 35 & 55 & 10 & Tanah liat \\
& & & & & & Tanah liat berlanau
\end{tabular}

Dapat dilihat bahwa pada masing-masing spot sampel sedimen memiliki kandungan persentase tanah yang berbeda-beda. Hal tersebut wajar terjadi dengan berbagai faktor angkutan sedimen akibat arus maupun gelombang dari laut. Kandungan pasir terbanyak pada spot 2, sedangkan terendah pada spot 1. Kandungan lanau terbanyak pada spot 9, sedangkan terendah pada spot 2. Kandungan lempung terbanyak pada spot 1, sedangkan terendah pada spot 2 .

Persentase terbesar dari keseluruhan ialah banyak mengandung lanau. Setelah dilakukan klasifikasi menggunakan USDA dapat dilihat ditabel bahwa tanah liat berlanau sangat mendominasi klasifikasi sedimen di muara sungai kapuas. Dengan hasil tersebut tentunya kita dapat mengetahui bahwa lanau juga sangat berpotensi tinggi untuk angkutan sedimen di muara sungai kapuas, jika hal ini tidak segera di ambil solusi dalam jangka tahun maka muara sungai kapuas terus mengalami pendangkalan yang akan mengganggu alur pelayaran menuju pelabuhan dwikora maupun sungai kapuas lebih hulu lagi. Maka dari itu, harus segera di lakukan bangunan pelindung muara agar angkutan sedimen dari luar muara dapat dihentikan khususnya pada mulut muara sungai kapuas yang terlihat sangat dangkal setelah dilakukannya pengukuran kedalaman, dimana hasil tersebut dapat dilihat pada klasifikasi morfologi dasar muara sungai kapuas.

\subsection{Klasifikasi Morfologi Dasar Muara}

Mengklasifikasikan morfologi dasar sungai kapuas dapat dilakukan kegiatan pengukuran kedalaman pada masing-masing titik sepanjang alur pelayaran. Hal ini tentunya sangat diperlukan bagi kapal-kapal yang akan melewati alur tersebut. Dimana dilakukan pengukuran batimetri sebanyak 21 spot menuju mulut muara sungai kapuas. Spot lokasi dapat dilihat pada Gambar 11. Titik tersebut berjarak $5 \mathrm{~km}$ dengan jarak masingmasing spot sejauh $250 \mathrm{~m}$.

Setelah dilakukannya pengukuran pada 21 spot tersebut, dilakukan pengolahan data menggunakan autocad. Jika gambar tersebut sudah didapat, maka dapat kita lihat secara horizontal bahwa pada mulut muara sungai kapuas terlihat dangkal dibanding spot menuju sungai kapuas. Dengan dilakukannya analisis berdasarkan kategori kemiringan Van Zuidam dapat dilihat bahwa kategori yang didapat untuk morfologi dasar muara sungai kapuas. Dengan hal tersebut nantinya dapat diketahui bahwa kontur muara sungai kapuas dapat diambil solusi untuk ditanggulangi kedangkalannya akibat penumpukan sedimen. 


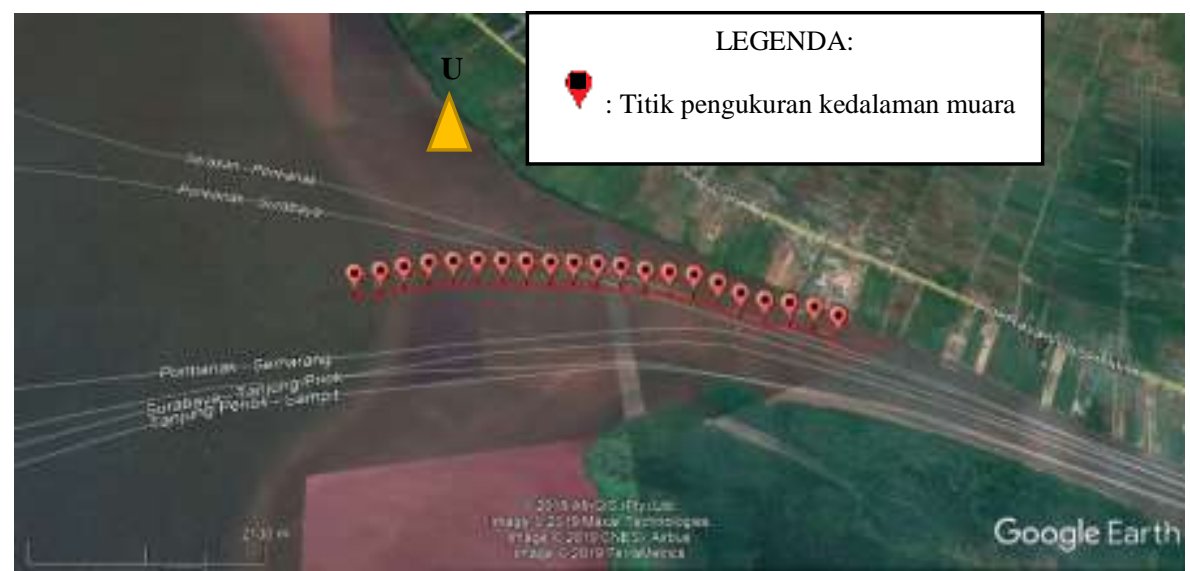

Gambar 11. Lokasi Pengambilan Data Batimetri

Tabel 2. Klasifikasi Morfologi Dasar Muara Kapuas

\begin{tabular}{|c|c|c|c|c|c|c|c|}
\hline \multirow{2}{*}{$\begin{array}{l}\text { Spot } \\
\text { Titik }\end{array}$} & \multicolumn{2}{|c|}{ Jarak antar titik } & \multirow{2}{*}{$\begin{array}{l}\begin{array}{l}\text { Kedalaman } \\
\text { koreksi*) }\end{array} \\
\text { (m) }\end{array}$} & \multirow{2}{*}{$\begin{array}{l}\text { Interval } \\
\text { (m) }\end{array}$} & \multirow{2}{*}{$\begin{array}{l}\text { Persentase } \\
\text { Kemiringan } \\
(\%)\end{array}$} & \multirow{2}{*}{$\begin{array}{l}\text { Derajat } \\
\text { Kemiringan } \\
\left({ }^{0}\right)\end{array}$} & \multirow{2}{*}{$\begin{array}{l}\text { Klasifikasi } \\
\text { Lereng**) }\end{array}$} \\
\hline & $(\mathrm{m})$ & jumlah & & & & & \\
\hline 1 & 0 & 0 & 8,7248 & - & - & - & - \\
\hline 2 & 250 & 250 & 7,8104 & 0,9144 & 0,3658 & 0,0037 & Datar \\
\hline 3 & 250 & 500 & 8,7248 & 0,9144 & 0,3658 & 0,0037 & Datar \\
\hline 4 & 250 & 750 & 6,8960 & 1,8288 & 0,7315 & 0,0073 & Datar \\
\hline 5 & 250 & 1000 & 7,8104 & 0,9144 & 0,3658 & 0,0037 & Datar \\
\hline 6 & 250 & 1250 & 5,9816 & 1,8288 & 0,7315 & 0,0073 & Datar \\
\hline 7 & 250 & 1500 & 5,6768 & 0,3048 & 0,1219 & 0,0012 & Datar \\
\hline 8 & 250 & 1750 & 4,7624 & 0,9144 & 0,3658 & 0,0037 & Datar \\
\hline 9 & 250 & 2000 & 3,8480 & 0,3048 & 0,1219 & 0,0012 & Datar \\
\hline 10 & 250 & 2250 & 4,1528 & 0,3048 & 0,1219 & 0,0012 & Datar \\
\hline 11 & 250 & 2500 & 3,5432 & 0,6096 & 0,2438 & 0,0024 & Datar \\
\hline 12 & 250 & 2750 & 4,4576 & 0,9144 & 0,3658 & 0,0037 & Datar \\
\hline 13 & 250 & 3000 & 5,6768 & 1,2192 & 0,4877 & 0,0049 & Datar \\
\hline 14 & 250 & 3250 & 4,1528 & 1,5240 & 0,6096 & 0,0061 & Datar \\
\hline 15 & 250 & 3500 & 3,2384 & 0,9144 & 0,3658 & 0,0037 & Datar \\
\hline 16 & 250 & 3750 & 5,6768 & 2,4384 & 0,9754 & 0,0098 & Datar \\
\hline 17 & 250 & 4000 & 4,4576 & 1,2192 & 0,4877 & 0,0049 & Datar \\
\hline 18 & 250 & 4250 & 5,9816 & 1,5240 & 0,6096 & 0,0061 & Datar \\
\hline 19 & 250 & 4500 & 3,8480 & 2,1336 & 0,8534 & 0,0085 & Datar \\
\hline 20 & 250 & 4750 & 2,9336 & 0,9144 & 0,3658 & 0,0037 & Datar \\
\hline 21 & 250 & 5000 & 2,6288 & 0,3048 & 0,1219 & 0,0012 & Datar \\
\hline
\end{tabular}




\begin{tabular}{lllllll}
\hline $\begin{array}{l}\text { Spot } \\
\text { Titik }\end{array}$ & Jarak antar titik & $\begin{array}{l}\text { Kedalaman } \\
\text { koreksi*) }\end{array}$ & Interval & $\begin{array}{l}\text { Persentase } \\
\text { Kemiringan }\end{array}$ & $\begin{array}{l}\text { Derajat } \\
\text { Kemiringan }\end{array}$ & $\begin{array}{l}\text { Klasifikasi } \\
\text { Lereng**) }\end{array}$ \\
\cline { 2 - 5 } & $(\mathrm{m}) \quad$ jumlah & $(\mathrm{m})$ & $(\mathrm{m})$ & $(\%)$ & $\left({ }^{0}\right)$ & \\
\hline Kemiringan Rata-Rata & & 0,4389 & 0,0044 & Datar \\
Kemiringan Dari Titik 1 Ke Titik 21 & & 0,1355 & 0,0014 & Datar
\end{tabular}

(Kemiringan Jarak 5000 m)

\begin{tabular}{ll}
\hline$*)$ & Kedalaman elevasi ditambah MSL+0,8 m \\
$* *)$ & Berdasarkan kategori kemiringan Van Zuidam 0-2 \% = Datar
\end{tabular}

Dapat kita lihat bahwa pada tabel 2 tersebut menyajikan dengan jelas kedalaman dan klasifikasi lereng pada masing-masing jarak spot pengukuran. Terlihat bahwa kedalaman yang terendah pada spot 21 yaitu pada mulut muara sungai kapuas sebesar 2,6 pada MSL+0,8 m. Dengan kemiringan lereng keseluruhan adalah datar berdasarkan derajat kemiringan yang dikategorikan berdasarkan kemiringan Van Zuidam sebesar 0,0014 derajat.

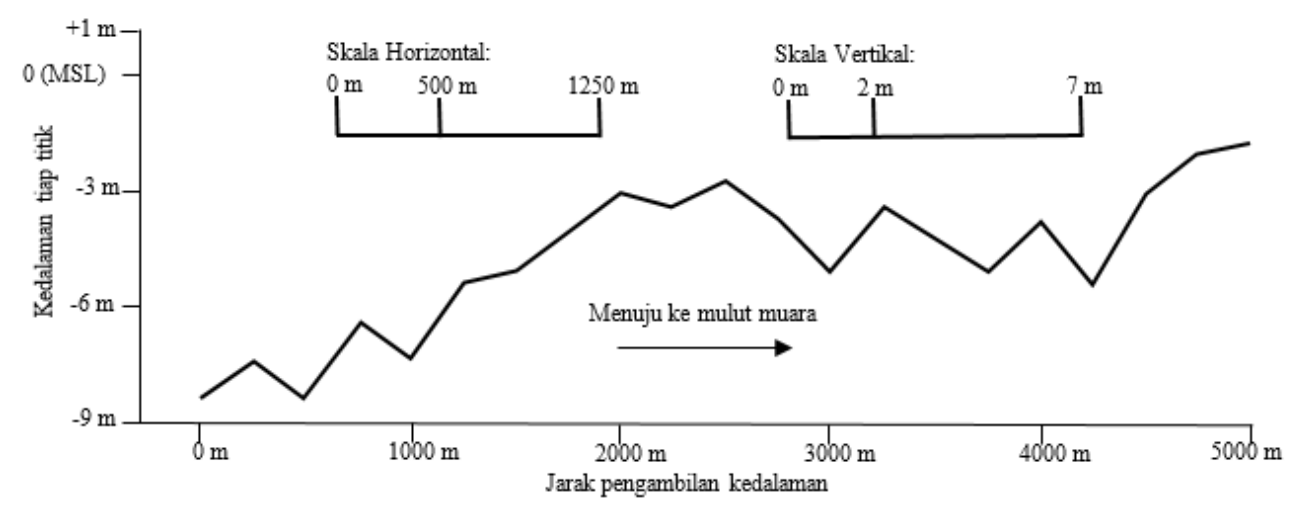

Gambar 12. Sketsa Kontur Muara Sungai Kapuas Sepanjang 5000 meter

Pada hasil gambar penampang horizontal kontur dasar muara sungai kapuas tersebut menggunakan skala vertikal dan horizontal yang berbeda agar dapat tersaji dalam bentuk gambar di lembar kertas. Tentu dapat dilihat semakin menuju mulut muara kedalaman perairan semakin dangkal. Hal ini menyulitkan kapal-kapal dimana draft kapal lebih dari $2 \mathrm{~m}$ untuk masuk ataupun bertambat di dermaga pelabuhan dwikora. Selama ini kapal-kapal tersebut menunggu hingga air pasang sampai mencukupi batas aman kapal tersebut melintasi alur pelayaran tersebut. Tentunya penulis sangat berharap akan dilakukan tindakan pelindungan muara sungai kapuas demi kelancaran pelayaran. Semakin lancarnya pelayaran yang mana membawa atau mengangkut barang-barang yang akan memenuhi kebutuhan masyarakat di Kalimantan Barat, dan juga tak terlepas dari meningkatkan pendapatan daerah.

\section{KESIMPULAN}

Berdasarkan hasil pengukuran lapangan dan analisa dapat disimpulkan beberapa hal berikut ini:

1. Dari hasil pengambilan data lapangan, menunjukkan bahwa batimetri di Muara Sungai Kapuas berkisar antara 2,6288 meter hingga 8,7248 meter pada MSL +0,8 meter.

2. Kontur dasar di Muara Sungai Kapuas di kategorikan Datar serta draft kapal yang melebihi 1,3 meter pada saat muka air rata-rata (MSL) harus menunggu air pasang baru bisa melewati muara.

3. Jenis sedimen dasar yang ada di 9 titik muara sungai kapuas dominan merupakan kategori tanah liat berlanau.

4. Berdasarkan hasil klasifikasi sedimen dasar muara sungai kapuas, sedimen bisa berasal dari pantai berlumpur yang mengalami abrasi oleh aliran air. Oleh karena itu solusi agar tidak dikeruk setiap tahunnya maka perlu dibangun bangunan pelindung muara (Jetty) agar sedimen tidak menumpuk di muara atau dinding penahan pantai agar tidak terjadi abrasi.

copyright is published under Lisensi Creative Commons Atribusi 4.0 Internasional. 


\section{UCAPAN TERIMAKASIH}

Pada kesempatan ini penulis mengucapkan terimakasih yang sebesar-besarnya kepada tim penyelenggara PKM 2018 dan dosen pembimbing kami serta seluruh pihak yang terkait dalam terjun langsung ke lapangan dan pengujian sampel di laboratorium, sehingga dapat menyelesaikan jurnal ini.

\section{DAFTAR PUSTAKA}

[1] A. Pamuji, M. R. Muskananfola, and C. A'in, "Pengaruh Sedimentasi Terhadap Kelimpahan Makrozoobenthos Di Muara Sungai Betahwalang Kabupaten Demak (The effects of sedimentation on macrozoobenthos abundance in Betahlawang Estuary of Demak)," Saintek Perikan. Indones. J. Fish. Sci. Technol., vol. 10, no. 2, pp. 129-135, 2015.

[2] B. Triatmodjo, "Perencanaan pelabuhan," Beta Offset. Yogyakarta, vol. 490, 2010.

[3] R. Bayu, "Pengukuran Debit dan Pengambilan Sampel." Balai Hidrologi dan Tata Air, Puslibang SDA,(http://raharjabayu. wordpress ..., 2011.

[4] W. B. Sukoro, H. Setiyono, and K. Kunarso, "Pengaruh Arus terhadap Sebaran Material Padatan Tersuspensi di PT. Pertamina Ru VI Perairan Balongan, Kabupaten Indramayu, Jawa Barat,” J. Oceanogr., vol. 4, no. 3, pp. 569-578, 2015.

[5] I. B. Pakpahan, "Analisis Transpor Sedimen Menyusur Pantai Dengan Menggunakan Metode Grafis Pada Pelabuhan Perikanan Tanjung Adikarta," J. Maroso, vol. 1, no. 01, 2013.

[6] R. Ikhwan, S. Saputro, and H. Hariadi, "Studi Sebaran Sedimen Dasar Di Sekitar Muara Sungai Pekalogan, Kota Pekalongan,” J. Oceanogr., vol. 4, no. 3, pp. 617-624, 2015.

[7] B. Triatmodjo, "Teknik pantai," Beta Offset, Yogyakarta, vol. 397, 1999.

[8] A. K. Nurdianti, W. Atmodjo, and S. Saputro, "Studi Batimetri Dan Kondisi Alur Pelayaran Di Muara Sungai Kapuas Kecil, Kalimantan Barat," J. Oceanogr., vol. 5, no. 4, pp. 538-545, 2016.

[9] Y. Arifianti, "Potensi Longsor Dasar Laut di Perairan Maumere," Bull. Vulkanol. dan Bencana Geol., vol. 6, no. 1, pp. 53-62, 2011.

[10] S. Sugiyono, "Metode Penelitian Kuantitatif, Kualitatif dan R\&D, Cetakan 8. Alfabeta, Bandung." 2009. 